\title{
Sandwaves and megaripples at Race Bank (UK) Offshore Wind Farm
}

\author{
S. M. Larsen and A. Roulund \\ DONG Energy A/S, Gentofte, Denmark
}

\author{
A. J. Brooks and A. Chaffey \\ ABP Marine Environmental Research Ltd, Southampton, United Kingdom
}

\begin{abstract}
The Race Bank Offshore Windfarm is part of the UK Round 2 extension. The windfarm comprises 91 6.3 MW turbines and two substations with total installed power of $573 \mathrm{MW}$. Construction work is scheduled for 2016/17. The windfarm is located in UK waters in the southern part of the North Sea about 30 $\mathrm{km}$ north of the Norfolk coastline and $30 \mathrm{~km}$ east of Lincolnshire. The Race Bank site has a diverse morphology located on large sandbanks with mobile sandwaves and megaripples and intersected by deeper featureless swales where clay soil formations are found close to or at the sea floor. The morphological complexity of the site was recognised early in the project development and numerous bathymetric surveys have been undertaken to help quantify sandwave migration rates and expected seabed variability. Morphological seabed assessments have been conducted by ABPmer throughout the project development. In the detailed design phase the ABPmer assessments have been combined with in-house DONG Energy analysis to provide design seabed levels and anticipated ranges of natural seabed changes within the lifetime of the windfarm. The paper presents an overall morphological characterisation of the windfarm site and provides examples of the very diverse seabed morphology encountered. When quantified, the morphological diversity can be absorbed in the monopile foundation design and cable installation contractors can select appropriate installation tools. The paper thus comes with a recommendation to ensure that bathymetric surveys in morphological active sites are carried out early and repeatedly during the project development stages.
\end{abstract}

\section{INTRODUCTION}

Dynamic bedform environments cause several challenges when designing and constructing an offshore windfarm. These include defining design seabed levels prior to installation and production of foundations; incorporating morphological changes into foundation and potential scour protection design; cable installation and choice of installation tools.

A detailed understanding of the seabed and its mobility is therefore important to gain as early in the project phase as possible.

Multiple bathymetric surveys, soil and geological characteristics can help provide that knowledge. A detailed study has been carried out on the Race Bank Offshore Windfarm site (ROW01) in UK waters, focusing on bedform classification, establishing migration rates and directions for different bedform types, design seabed levels and seabed level at time of scour protection installation.

The paper presents an overall morphological characterisation of the ROW01 windfarm site and provides examples of the very diverse seabed morphology encountered. First, the site is described with oceanographic data and soil conditions. Then an overview of the surveys conducted in the area is provided. The seabed morphology including bedform characteristics and migration rates are discussed. Finally examples of the different morphology encountered at the site are presented.

\section{SITE DESCRIPTION}

\subsection{Site location}

The ROW01 site is located in UK waters in the southern part of the North Sea about $30 \mathrm{~km}$ north of the coastline of Norfolk and $30 \mathrm{~km}$ east of Lincolnshire (figure 1). 


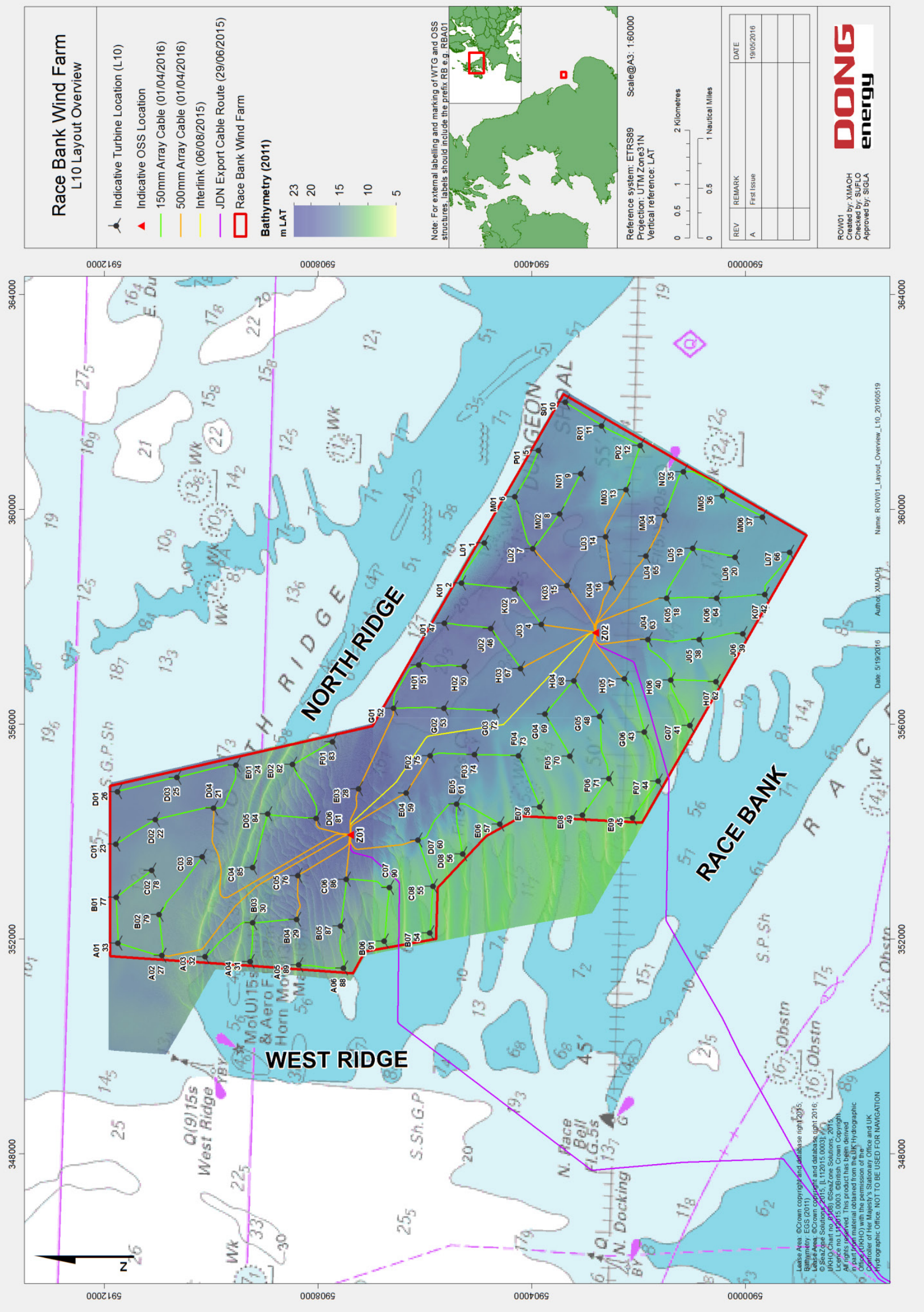

Figure 1. ROW01 OWF site layout and bathymetry from 2011 on top of UKHO Chart no. 0108. 


\subsection{Seabed level}

Seabed level at turbines varies from $-11 \mathrm{~m}$ to $-22 \mathrm{~m}$ relative to LAT $(-14 \mathrm{~m}$ to $-25 \mathrm{~m}$ relative to MSL) over the wind farm area. A full coverage bathymetric dataset is shown in figure 1 .

\subsection{Currents}

The tidal currents at the ROW01 site are dominating in the directions of NW and SE (Figure 2). In figure 3 a timeseries of current velocity and water level is shown for March 2007.

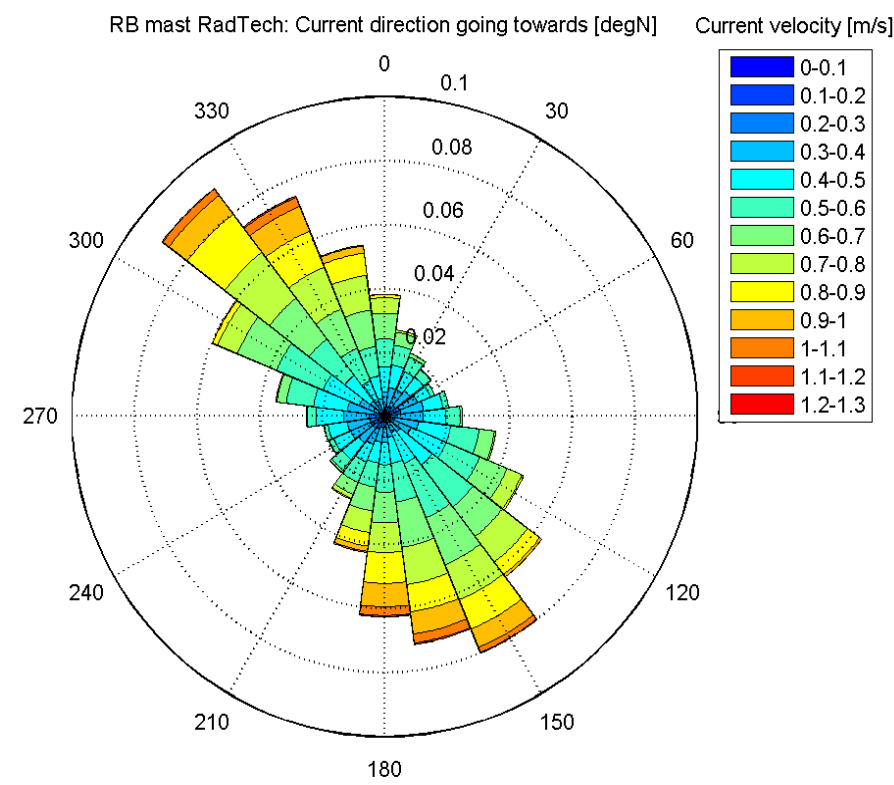

Figure 2. Measured current rose (depth averaged) for the site. Current direction going towards [ $\operatorname{degN}]$.

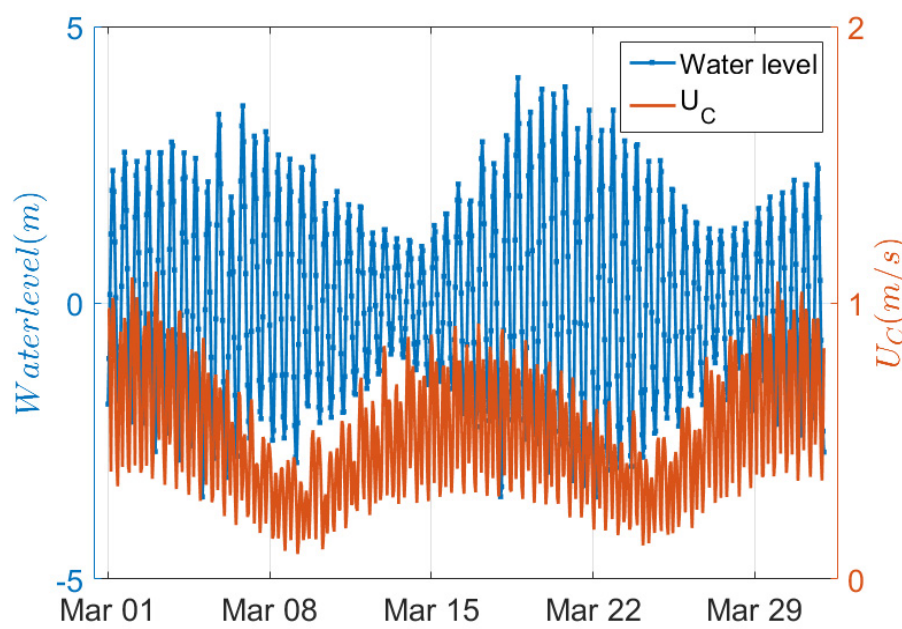

Figure 3 . Time series of current velocity $\left(\mathrm{U}_{\mathrm{C}}\right)$ and water level for March 2007.

\subsection{Waves}

ROW01 is mainly exposed to waves from the North as illustrated by the wave rose in Figure 4. The wave rose is based on outputs from a regional scale wave model created by DHI calibrated and validated using oceanographic data collected during the projectspecific survey campaigns. In figure 5 a scatter plot of peak wave period $\left(\mathrm{T}_{\mathrm{P}}\right)$ and wave height $\left(\mathrm{H}_{\mathrm{S}}\right)$ is shown.

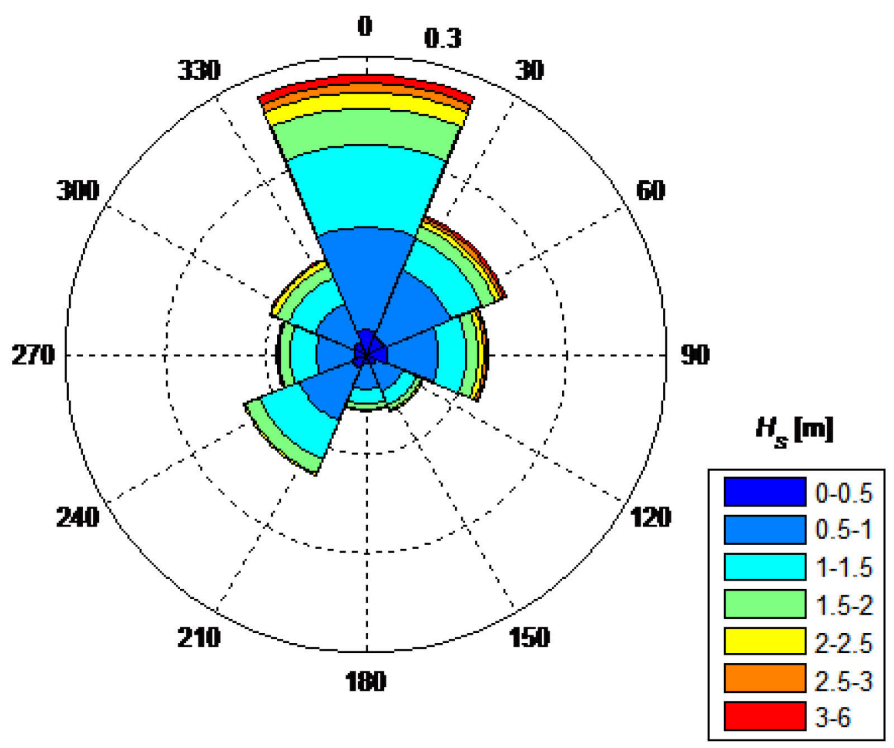

Figure 4. Mean wave direction $[\operatorname{degN}]$. Wave rose based on DHI regional model for the site.

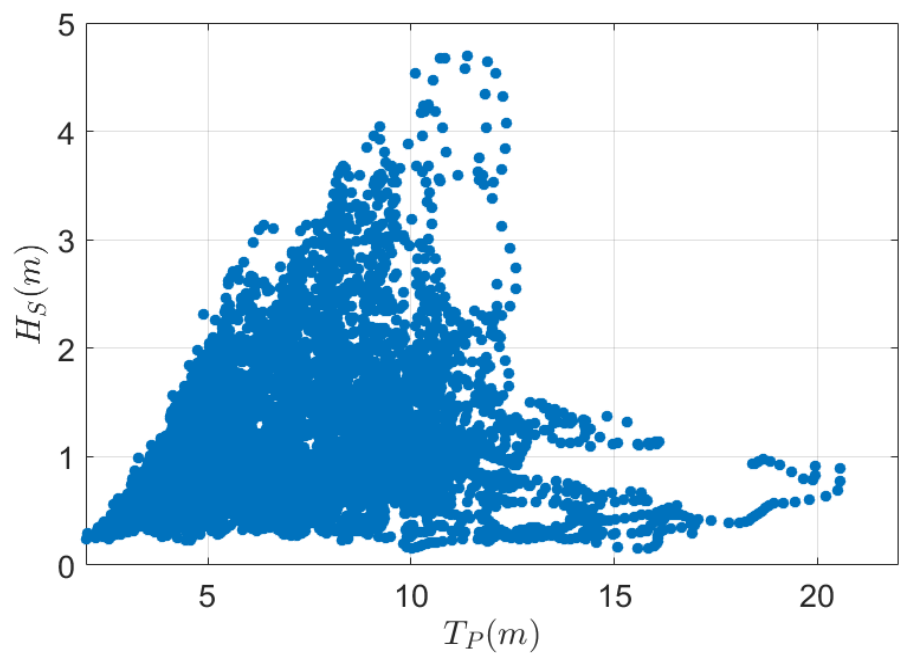

Figure 5. Scatter plot of Hs and Tp for the period of $31^{\text {st }}$ Dec $2006-1^{\text {st }}$ Jan 2008.

\subsection{Geology}

Across the entire ROW01 OWF the Swarte Bank formation (SBF) glacial deposit is directly overlaying the Cretaceous Chalk bedrock.

On top of the SBF is the Egmond Ground Formation (EGF) which is overlain by the wide but discontinuous Bolders Bank Formation (BBF). The $\mathrm{BBF}$ consists of firm to very hard slightly sandy, slightly gravelly clay with sand beds varying in thinkness and composition. The sporadically occurring Botney Cut Formations follows

The top layer consists of unconsolidated Holocene sediments of sands and gravels making up the sandbank and sandwave features observed within the ROW01 OWF. Because of the bedforms this layer thickness varies from 1 meter up to more than 8 me- 
ters. In the deeper areas where the large bedforms are absent, the top sand layer is very thin with harder clay immediately below (figure 1) whereas the shallower areas have the rather thick sandy layer on top.

The top of the cretaceous Chalk solid geology shows multiple channels as well as an inclination towards northeast. As the depths of the solid geology are often greater than $40 \mathrm{~m}$ below seabed, the solid geology will not directly influence seabed morphology over timescales relevant to the project (ABPmer, 2015).

\section{SURVEYS}

The bathymetrical surveys listed in Table 1 all have sufficient resolution to resolve the morphology of bedforms present within the site and have all been used to inform the bedform analyses.

Table 1. Datasets applied in the study

\begin{tabular}{|c|c|c|c|}
\hline Year & Collected & Contractor & Coverage \\
\hline 2015 & Mar - Apr 2015 & FugroEMU & $\begin{array}{l}\text { WTG positions, ar- } \\
\text { ray cables and full } \\
\text { coverage at North } \\
\text { Ridge }\end{array}$ \\
\hline 2015 & Mar - May 2015 & Spectrum & Partly coverage \\
\hline 2014 & Aug - Oct 2014 & MMT & Most of site \\
\hline 2014 & Sep - Oct 2014 & EGS Ltd & Array cable route \\
\hline 2012 & Jul - Oct 2012 & Gardline & $\begin{array}{l}\text { WTG locations and } \\
\text { cable routes }\end{array}$ \\
\hline 2011 & $\begin{array}{l}\text { Dec } 2010 \text { and } \\
\text { Apr - Aug } 2011\end{array}$ & EGS Ltd & Full site \\
\hline $2005 /$ & Nov $2005-$ & $\begin{array}{l}\text { EMU/Osiri } \\
\mathrm{s}\end{array}$ & Full site \\
\hline 2006 & Aug 2006 & & \\
\hline
\end{tabular}

\section{METHOD}

Profiles have been extracted along and across the bedform migration direction for every WTG position in the site from every available bathymetry survey data. From the profiles individual bedforms were identified and their dimensions determined. Based on the trough and crest movements the distances and migration speeds are determined

To determine the migration rates of the sandwaves the crest and trough positions are used. Because of smaller bedforms imposed on the sandwaves some uncertainties are related to determining the exact location of the trough and crest. These locations have been determined by visual inspection.

Furthermore, the use of bathymetric data induce uncertainties in both vertical and horisontal directions depending amongst others on the survey quality and weather conditions during the survey campaign.

The analysis can only be conducted at the scale of the lowest accuracy although a better vertical accu- racy is achieved from the 2012, 2014 and 2015 bathymetries. The 2011 EGS bathymetry have the overall worst case vertical and horizontal accuracy measure of $+/-0.6 \mathrm{~m}$ and $6.2 \mathrm{~m}$ respectively is therefore used for the uncertainty estimate.

\section{MORPHOLOGY}

\subsection{Bedforms}

Ripples are the smallest bedform type described here and can be found at various locations. Because of the low amplitude (see table 2) their presence does not affect the foundations design or cable burial depths.

Megaripples are larger than ripples and can be either long- or short-crested (Gallagher, 2011). They are also very mobile (see table 2 ) and in areas where sandwaves and banks are stable, these will constitute the seabed change.

Sandwaves are large independent straight-crested bedforms, which develops under lower flow velocities than ripples and megaripples. Sandwaves are often overlain by smaller bedforms like ripples and megaripples (Reineck and Singh, 1980). Their heights can reach $25 \%$ of the water depth (McCave, 1971). As the sandwaves are larger than both ripples and megaripples their migration speeds are slower, due to the amount of sediment to be moved. However, sandwaves are still migrating fast enough to impact the foundation and cables.

Sandbanks are very large features, which have slower migration rates than the smaller bedforms, but still faster than ridges and larger bedforms. They are of interest to offshore construction, since that are very common, relatively mobile and have a large impact of the water depth. 
Table 2. Description of different bedform classes and typical properties.

\begin{tabular}{llllll}
\hline Bedform type & Related flow & Scale & Length $(\mathrm{m})$ & Height (m) & Mobility \\
\hline Ripples & Wave and tide & Micro & $0.1-1$ & $0.01-0.1$ & $\begin{array}{l}\text { Hours } \\
(1 \mathrm{~m} / \text { day })\end{array}$ \\
Megaripples & $\begin{array}{l}\text { Tide (near } \\
\text { bed currents) }\end{array}$ & Micro & $1-30$ & $0.1-1$ & $\begin{array}{l}\text { Hours }- \text { Days } \\
(-100 \mathrm{~m} / \text { year) }\end{array}$ \\
Tide (near bed \\
$\begin{array}{l}\text { residual currents) } \\
\text { Tide (depth averaged } \\
\text { residual currents) }\end{array}$ & Meso & $30-700$ & $1-5$ & $\begin{array}{l}\text { Days }- \text { Decades } \\
(-10 \mathrm{~m} / \text { year })\end{array}$ \\
Sandbanks & Macro & max. 15,000 & $5-15$ & $\begin{array}{l}\text { Years }- \text { Centuries } \\
(1 \mathrm{~m} / \text { year })\end{array}$ \\
\hline
\end{tabular}

* From ABPmer (2015), based on classifications by Morelissen et al. (2003) and Knaapen (2005).

\subsection{Morphological description}

North Ridge sandbank and Race Bank sandbank are two distinct features but part of a single sandbank system covering the ROW01 OWF. They are orientated approximately southeast by northwest and meet in the western part of the site in an area termed 'West Ridge' (figure 1). Despite being linked, the sandbanks have slightly different evolution characteristics. Race Bank is considered to be fairly stable, with little to no migration. The North Ridge sandbank however, is actively evolving with the crests migration towards the northeast at a rate of several meters per year.

In the northernmost part as well as in the southeastern part of the site the seabed is typically flat and featureless and only shows limited seabed changes related to an accretion trend (ABPmer, 2008a; ABPmer 2012a) (figure 1). However, over time the slowly migrating North Ridge is likely to encroach on the featureless northern part of the site resulting in the introduction of the sandbank and overlying bedforms.

Superimposed upon the sandbanks are bedforms of varying sizes. To the west of the site and overlying the Race Bank sandbank are the Race Bank sandwaves, which are large bedforms with a wavelength of approximately $400 \mathrm{~m}$ and heights of 2 to 5 $\mathrm{m}$. As the bedforms are migrating towards northwest over time, both erosion and accretion will influence the areas. ABPmer (2012b) identified evidence of bifurcation and potential future convergence of sandwaves due to the varying migration speeds within the bedform field.

In the area just south of the northerly migrating North Ridge and on the sandbank itself, the bedforms are highly mobile and the morphology is complex. The $200 \mathrm{~m}$ long and $1 \mathrm{~m}$ high sandwaves are migrating towards the northwest with their crests perpendicular to the underlying North Ridge sandbank bedform, which itself is migrating towards the northeast (ABPmer, 2015).

\subsection{Zoning of site}

The Race Bank site is located in between a number of seabed formations as described in section 4.2.

Figure 6 provides details of the morphological 'behaviour zones' within the Race Bank site as considered by ABPmer. The purpose of these zones is to develop bespoke indices for process, sediment type and morphology based on subareas that exhibit key behavioural similarities. The zones are summarised below:

Zone 1: The prograding northern edge of North Ridge which is migrating in a northerly direction

Zone 2a: The bedforms in this zone comprise of small sandwaves with orientations generally consistent with migration towards the north. These features are however smaller in size compared with the Race Bank sandwaves to the south (Zone 2b)

Zone 2b: The main body of the Race Bank features, which is made up of northerly migrating large sandwaves

Zone 3a: The relatively flat and featureless area situated between Race Bank and North Ridge

Zone 3b: Southern margin of North Ridge - Dudgeon Shoal. Characterised by the presence of low amplitude $(<0.5 \mathrm{~m})$ megaripple bedforms.

Zone 4: The western part of North Ridge. This area comprises northerly migrating large sandwaves and north-westerly migrating smaller sandwaves

Zone 5: Flat featureless seabed further north of North Ridge, no bedforms are present, but the area is in the pathway of the migrating North Ridge. 


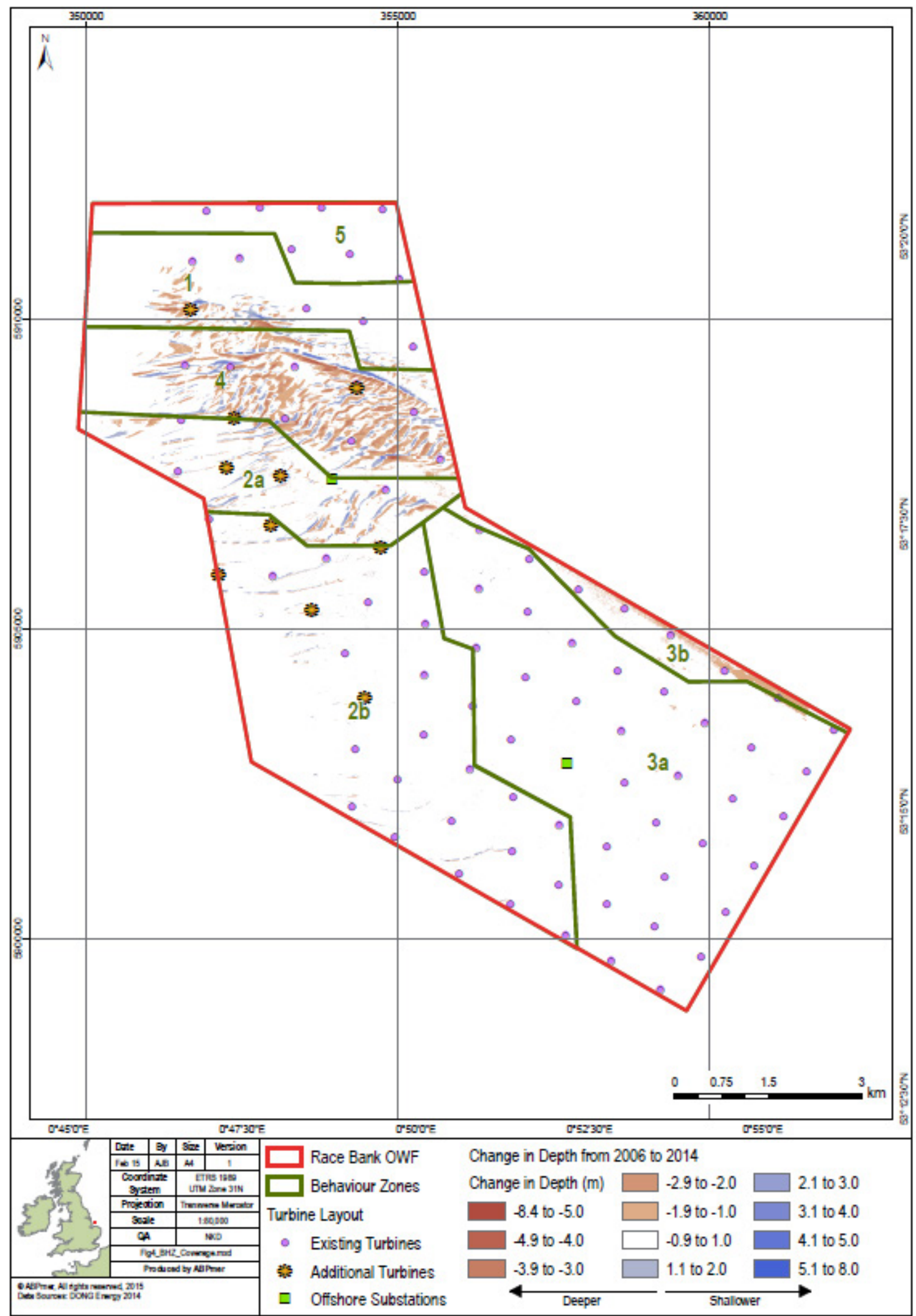

Figure 6. The ROW01 OWF site divided into zones based on morphological behavior (ABPmer, 2015).

\subsection{Examples and description of zones}

The bedforms and charateristics of the individual behavior zones are described in greater detail in the following section. 


\section{Zone 2a}

This Behaviour Zone is considered a transition zone between the northerly migrating large sandwaves to the south (Zone $2 \mathrm{~b}$ ) and the smaller northwesterly migrating sandwaves to the north (Zone 4). There does appear to be some bifurcation or convergence of the sandwave crests within this zone. Therefore, the ongoing evolution of these features will affect bed levels at the locations of turbines in this area.

The trend within this zone is primarily one of fluctuating seabed depths in relation to the migrating sandwaves. The occurrence of the deepest and shallowest seabed depths will vary depending on the proposed turbine locations, whereby the seabed depths will shallow as the sandwave reaches the turbines and deepen as the crests pass (see Figure 7).

Besides the larger sandwaves, megaripples with $\lambda \approx 10 \mathrm{~m}$ and $\eta \approx 0.1-0.4 \mathrm{~m}$ are present. In the areas close to the turbine positions the megaripples are low in amplitude and therefore not critical for foundations. However, the larger fast migrating bedforms may influence the cable burial depth.
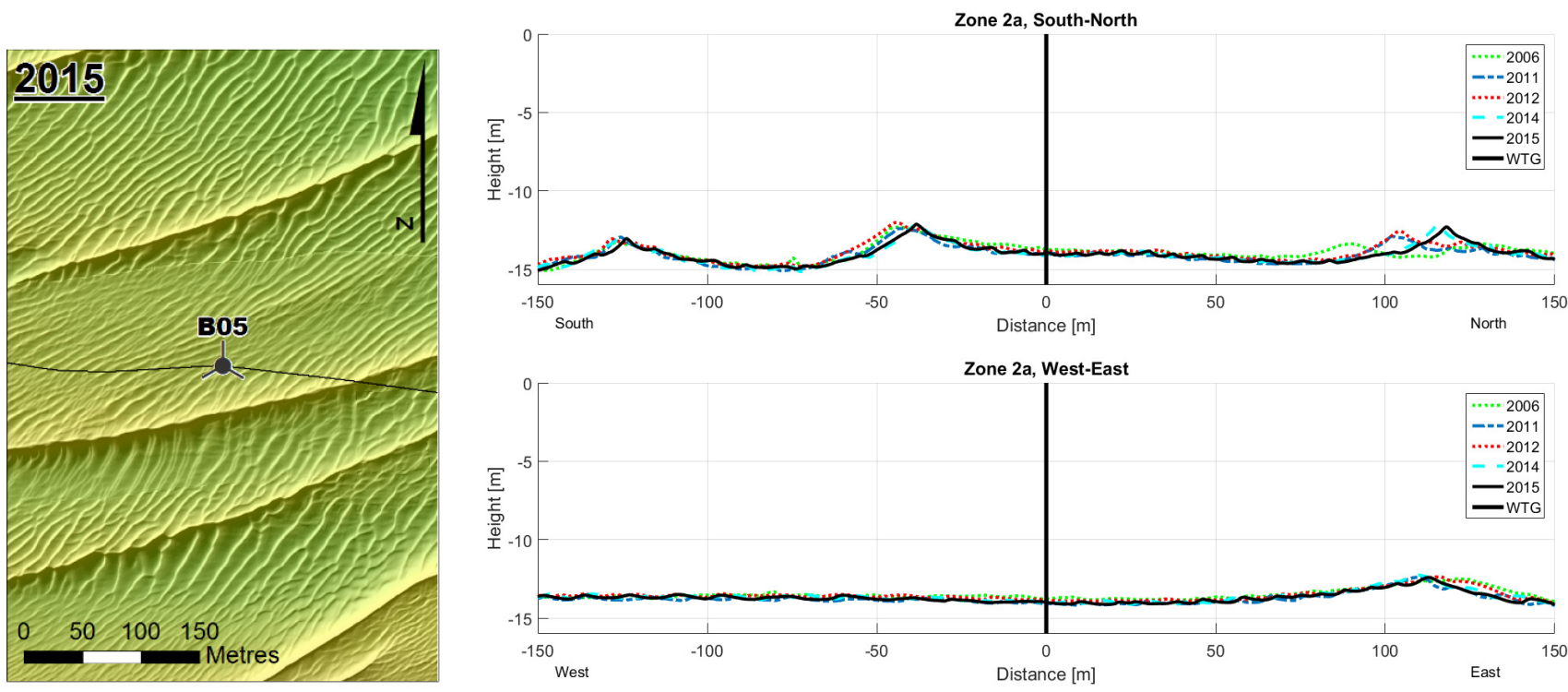

Figure 7. Zone 2a. Morphology surrounding position B05.

\section{Zone 2b}

The turbine positions within this zone are located amongst the Race Bank sandwaves. Seabed depths at the proposed turbine locations within the zone will gradually change to the degree that sandwave peaks and troughs moves towards and away from the turbine positions. The speed at which these changes will occur is considered to be relatively slow in relation to the sandwave migration speed (Table 3). However, where changes occour, these would be relatively large due to the magnitude of the sandwaves within this zone. Figure 8 shows an example of the morphology representative for zone $2 b$.
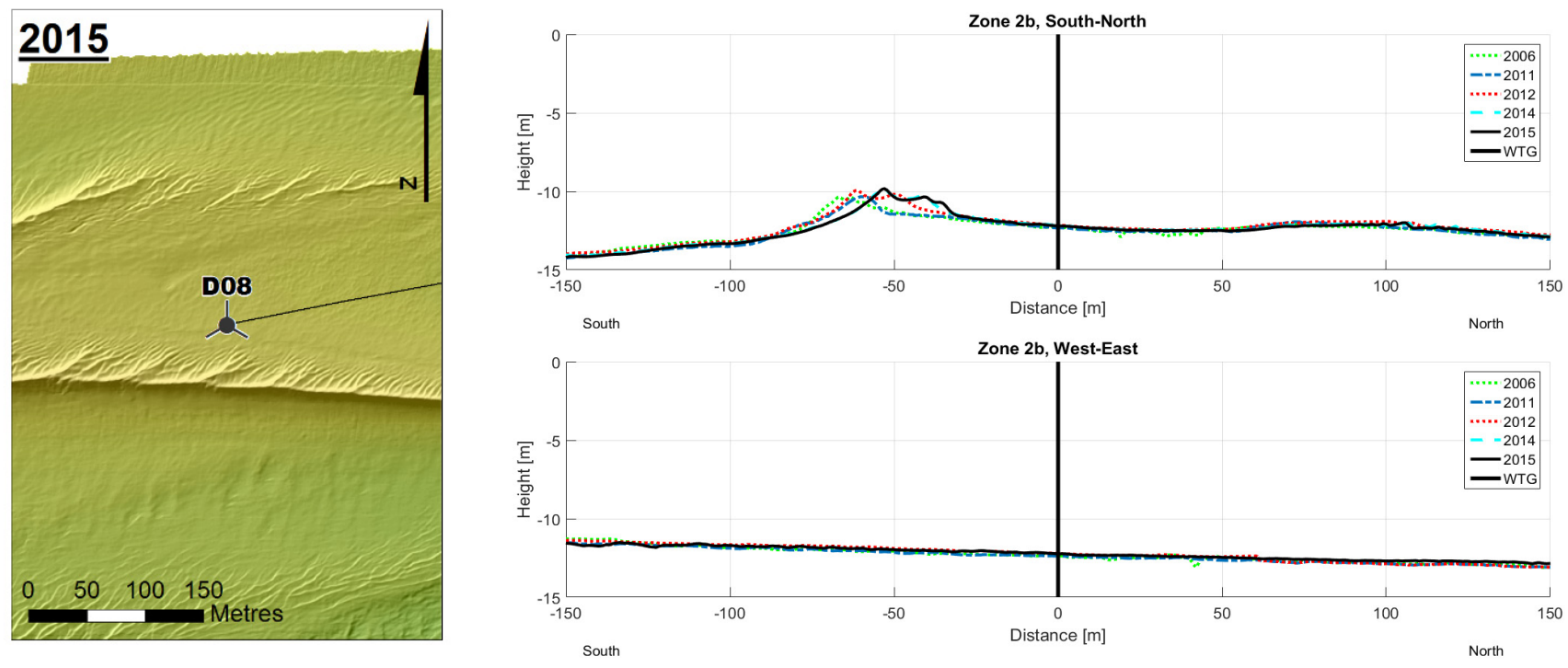

Figure 8 . Zone 2b. Morphology surrounding position D08.

Zone 3b 
This behaviour Zone is characterised by the presence of low amplitude (i.e. $<0.7 \mathrm{~m}$ ) bedforms migrating towards the northwest (see Figure 9). These bedforms are likely to be migrating rapidly in order of tens to a few hundred of meters per year.
Because of their fast movement, the larger megaripples can affect installation processes related to foundation-cable interfaces. Furthermore, it can be challenging to define the burial depth of array cables in areas with megaripples resulting in a risk of exposed cables.
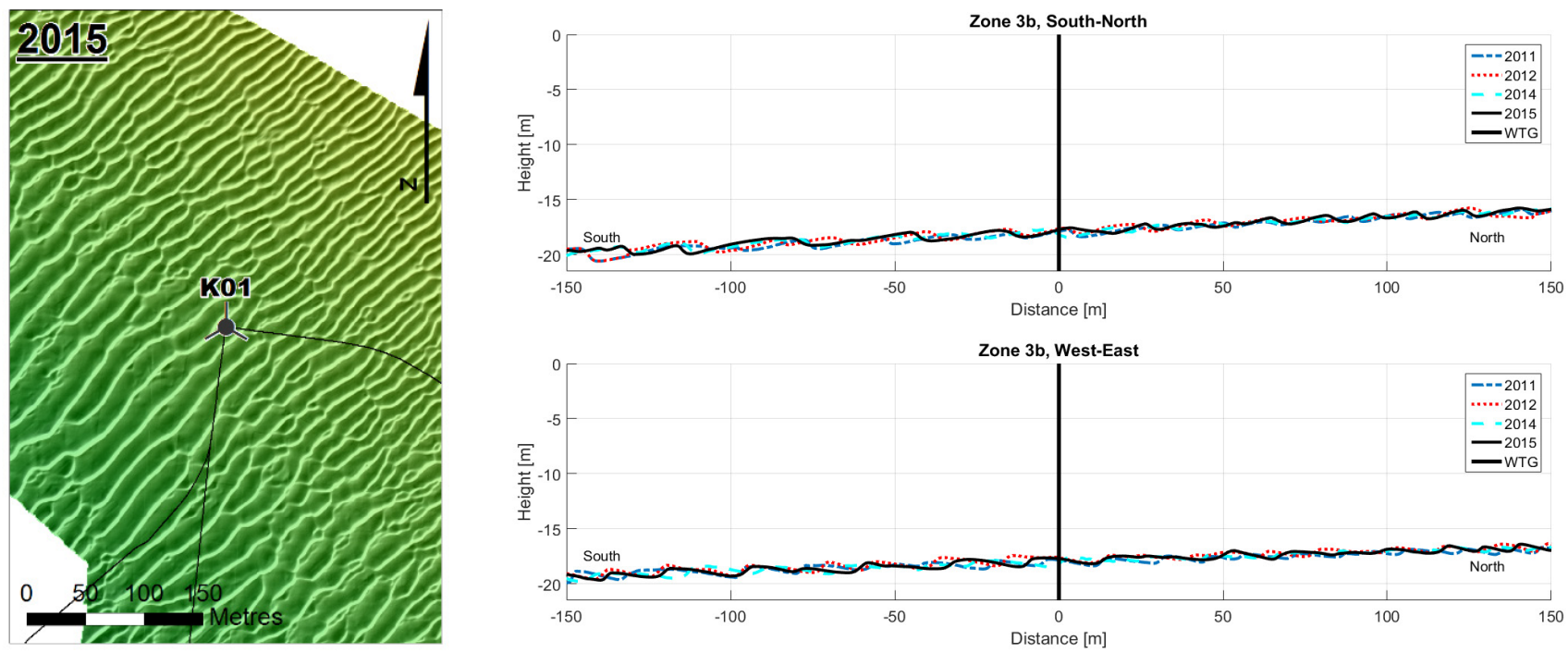

Figure 9. Zone 3b. Morphology surrounding position K01.

\section{Zone 4}

The area just south of the North Ridge is higly dynamic resulting in very fast migrating bedforms, including sandwaves. The turbines within this zone are located amongst the sandwaves on the southern flank of the North Ridge sandbank. Future changes at the turbine locations will primarily be dictated by migration of the sandwave features present on the sandbank and less by the migration of the sandbank itself.

The overall trend of the proposed seabed levels at the turbine locations is fluctuating depths (see Figure $10)$.

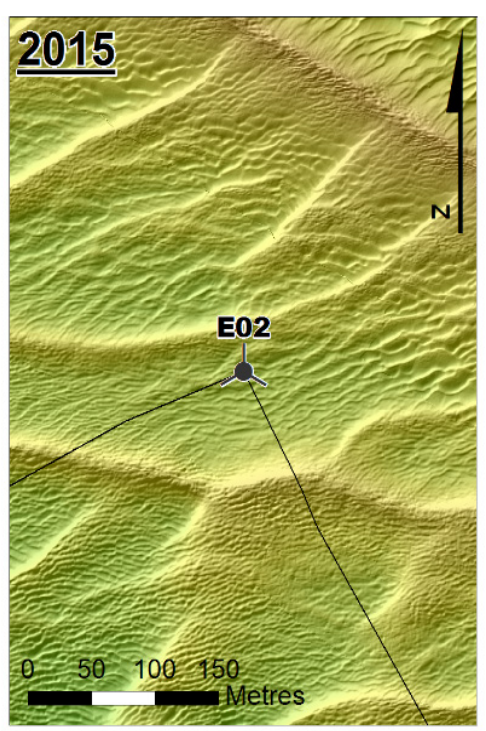

In this zone, it is possible that quite significant (i.e. $> \pm 1.5 \mathrm{~m}$ ) variations in bed level may occur over short timescales (i.e. a couple of years). Such changes may arise as a consequence of the potentially fast rates of bedform migration allied with the close proximity of turbines to moderately large bedforms.

The sandwaves in this area are both large and can migrate a fair distance during the lifetime of the park. Therefore, they are responsible for the most severe challenges for design and installation of foundations and cables.
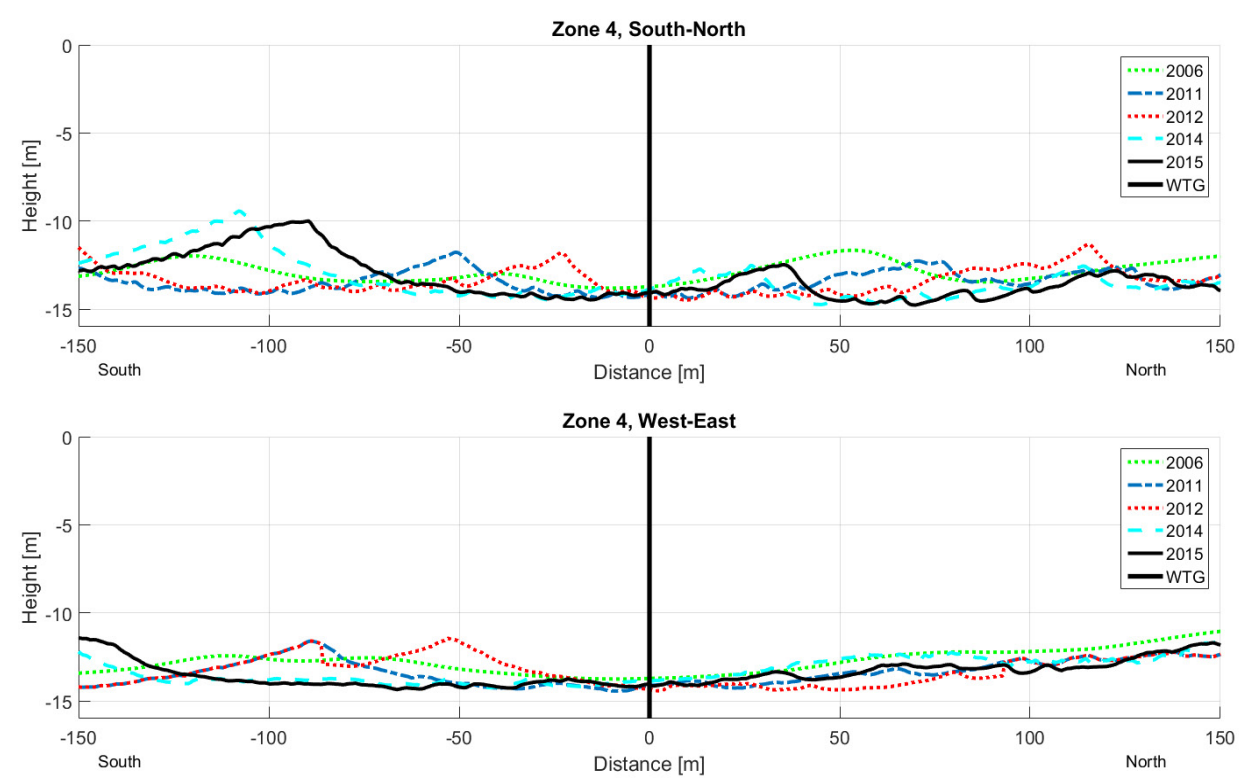

Figure 10. Zone 4. Morphology surrounding position E02. 


\section{Zone 1, 3a \& 5}

The three zones $(1,3 a \& 5)$ are all relatively flat and the seabed within these zones is predominantly flat and featureless, with no bedform features present to cause large fluctuations in the seabed levels (see Figure 11 as an example). Zones 1 and 5 are located north of the North Ridge feature. Difference calculations between the available bathymetric datasets indicate that the ridge crests on North Ridge are still evolving and migrating towards the northeast. On this basis, the seabed depths at many of the turbines will start to shallow as the bank approaches the turbines. The timing at which this is anticipated to occur varies depending on the proximity of the turbine to the bank, but the ridge crest is not anticipated to move past any of the turbine positions during the lifetime of the project.

In zone 1 Small megaripples cover the site having lengths $(\lambda)$ of approximately $10 \mathrm{~m}$ and heights $(\eta)$ of only $0.2 \mathrm{~m}$ and are therefore without impact on the foundations and the cable installation. In the area closest to the North Ridge larger bedforms are present having $\lambda \approx 90 \mathrm{~m}$ and $\eta \approx$ of $0.7 \mathrm{~m}$. In the surveyed 9-year period these larger bedforms have been stable and are therefore not anticipated to have a larger impact on the windfarm

Zone $3 \mathrm{a}$ is devoid of bedforms and would appear to be relatively consistent in depth, with generally only a thin veneer of sediments overlying the outcropping clay. The historical data suggests only small changes in the recorded seabed level, with small increases and decreases across the majority of the zone and turbine locations. These changes are typically less than $0.5 \mathrm{~m}$ and are interpreted to be due to sand patches (possibly sand ribbons) being transported towards the northwest through the zone.
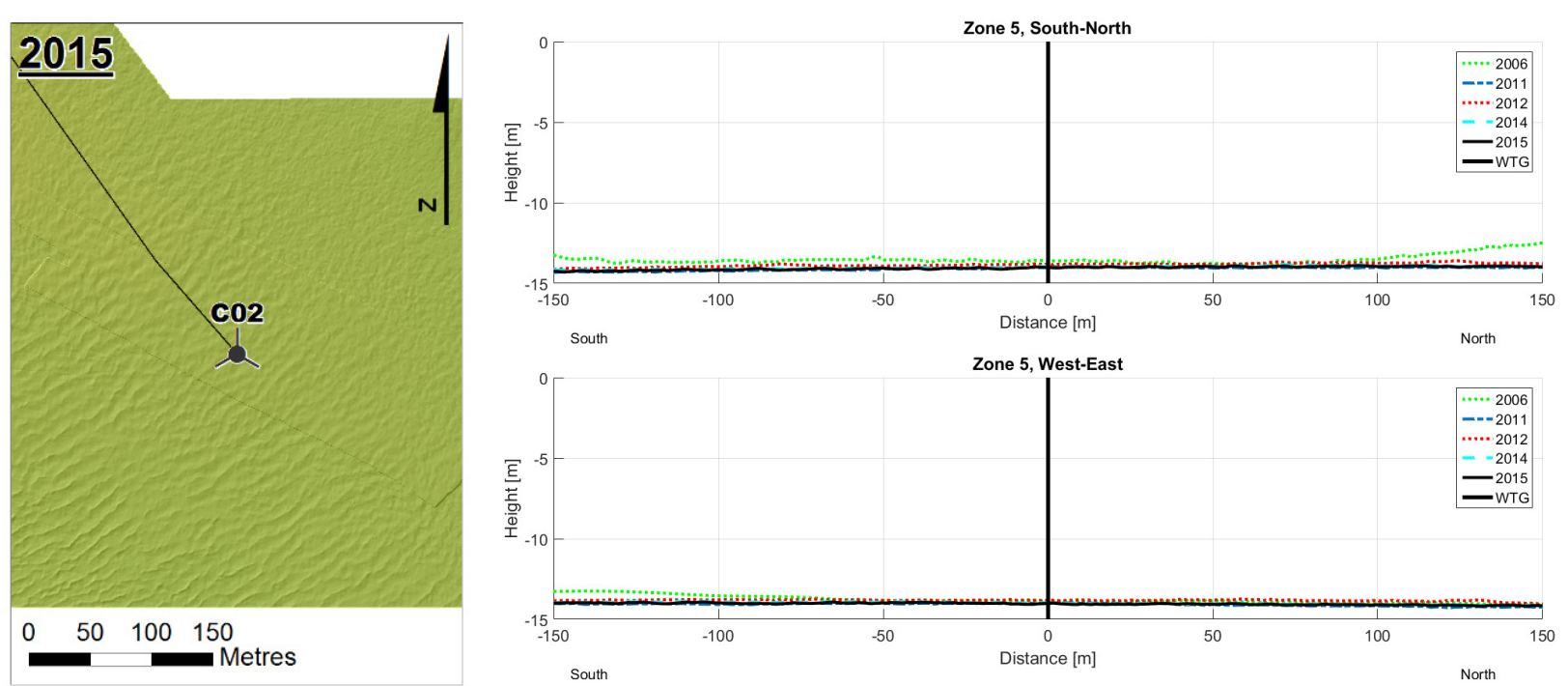

Figure 11. Zone 5. Morphology surrounding position C02.

\subsection{Bedform migration rates}

Based on survey data from 2006, 2011, 2012, 2014 and 2015 average migration rates for the different bedform types have been estimated. The overall pattern shows bedform orientation in a north-south direction with migration direction of the bedforms towards the north-west.Migration rates have been related to the bedform types within the respective behaviour zones and estimates are given in Table 3 . These estimates of migration rates have subsequently been used to inform understanding of future bed levels within the site over various timescales relevant to the construction and operation of the windfarm.
Table 3. Estimated Migration rates based on bathymetry from 2006, 2011, 2012, 2014 and 2015 for the different zones in Figure 6. N/A are used when no bedforms are present.

\begin{tabular}{lll}
\hline Behaviour & \multicolumn{2}{l}{ Assessed average Migration rates } \\
\cline { 2 - 3 } Zone & Bedform type & $\mathrm{m} / \mathrm{yr}$ \\
\hline 1 & North Ridge & 5.0 \\
& Sandwaves & 9.0 \\
$2 \mathrm{a}$ & & 27.0 \\
$2 \mathrm{~b}$ & & 7.0 \\
$3 \mathrm{a}$ & & $\mathrm{N} / \mathrm{A}$ \\
$3 \mathrm{~b}$ & Sandwaves & N/A \\
& Megaripples & Very fast $(\sim 100 \mathrm{~m} / \mathrm{yr})$ \\
4 & North Ridge & 13.0 \\
& Sandwaves & 31.0 \\
5 & & N/A \\
\hline
\end{tabular}




\section{DISCUSSION}

As described the morphology of the Race Bank site varies a lot. The ridge system across the site and the large quantities of sandy material in this area are probably the most responsible for that (see Figure 1). The presence of the ridge reduces the water depth and the local flow patterns around it, which is why the most mobile bedforms are seen in the area nearby the ridge. Design seabed levels and actual seabed height at installation is therefore very difficult to predict before the construction phase and the only way to give a qualified estimate is by having a good understanding of the behavior of the seabed and bedforms from survey data preferably collected over a large period of time.

The flat areas in deeper water and without bedforms is where the hard clay layers are close to the seabed surface. The foundations and cables located in this area are not as vulnerable to scour development as the geotechnical analysis shows clay close to the seabed, preventing or slowing down scour development. Furthermore, the seabed is relatively stable and design seabed levels as well as seabed level at installation time is easier to predict based on bathymetric survey data.

In order to make reliable predictions of bedform migration rates and bedform movements the quantity, quality and timespan of surveys play an important role. It is important to gain knowledge on the characteristics of the area early in the project phase and to build on this understanding as the project moves into the detailed design phase. For very dynamic locations, it may also be valuable to increase survey frequency towards time of installation to allow for last minute changes if the seabed is not looking as expected.

\section{CONCLUSION}

The morphological complexity of the Race Bank site was recognised early in the project development and numerous bathymetrical surveys have been undertaken to quantify sandwave migration rates and expected seabed variability. Morphological seabed assessment have been conducted by ABPmer throughout the project development. In the detailed design phase the ABPmer assessments have been combined with in-house DONG Energy analysis to provide design seabed levels and ranges of natural seabed changes within the lifetime of the windfarm.

The experiences from ROW01 OWF show the importance of frequent bathymetry surveys from an early stage in the project in order to determine design seabed levels in due time for cable hole design.

For very dynamic locations it may also be valuable to increase survey frequency towards time of installation to allow for last minute changes.
A high survey frequency is of course extra important if the seabed is dynamic like it is at the Race Bank sandbank system.

\section{REFERENCES}

ABPmer, 2008a. Race Bank Morphological Analysis. ABPmer Marine Environmental Research Ltd., Research Report No. R.1406.

ABPmer, 2012a. Race Bank Morphological Update: Analysis of Future Bed Levels. ABPmer Marine Environmental Research Ltd., Research Report No. R.1951.

ABPmer, 2012b. Race Bank Sandwave Analysis. ABPmer Marine Environmental Research Ltd., Research Report No. R.1947.

ABPmer, 2015. Race Bank Morphological Update 2015: Analysis of Future Bed Levels. ABPmer Marine Environmental Research Ltd., Research Report No. 2396.

Gallagher, E. L., 2011. Computer simulations of wellorganised megaripples in the nearshore. Journal of geophysical research, Vol. 116, F01004, doi:10.1029/2009JF001473

Knappen, M. A. F., 2005. Sandwave migration predictor based on shape information. Journal of Geophysical Reshearch, 110, F04S11 (doi:10.1029/2004JF000195).

McCave, I. N., 1971. Sand waves in the North Sea off the coast of Holland. Marine Geology 10, 199-225.

Morelissen, R., Hulscher, S., Knappen, M., Németh, A. \& Bijker, R., 2003. Mathematical modelling og sandwave migration and the interaction with pipelines. Coastal Engineering, 48, 197-209 (doi:10.1016/S0378-3839(03)00028$0)$.

Reineck, H. E. \& Singh, I. B., 1980. Depositional sedimentary Environments - wi-h reference to Terrigenous Clastics. Springer-Verlag, Berlin, Heidelberg, New York. 